indicate that a substantial proportion of all premature work disability pensions would not have been necessary with efficient weight control. Contrary to the widely held belief, " the benefits of preventing overweight seem to be greater in women than in men, at least in terms of the preservation of functional capacity.

Preventing overweight would have had only a negligible effect on mortality in the present study population; this confirms the results of several studies that document only a weak association between high body weight and mortality. ${ }^{12}$ It is not entirely clear why overweight conveys a clearly increased risk of disability without affecting mortality. Overweight may be associated with some beneficial or protective traits favouring survival, but the possible extra years of life are likely to be of poor quality and of limited value.

In the present study the body mass index associated with the smallest risk of work disability, and presumably with the best health, was lower than that associated with the greatest longevity, the customary basis for defining desirable or ideal weight. ${ }^{13}$ The value of weight standards based on longevity rather than on the quality of life should be seriously questioned.

Can the results of this study be generalised? The study cohort was large and representative of the occupationally active and presumably healthy ${ }^{14}$ Finnish population, ${ }^{2}$ the attendance rate in the study was good, ${ }^{2}$ and the ascertainment of deaths ${ }^{4}$ and disability was complete. The data should therefore allow fairly unbiased conclusions to be drawn about the impact of body weight on the health of employed Finns. No comparable data are, to the best of our knowledge, available from other countries, and in view of the complex interplay of multiple cultural factors in determining weight on one hand and health on the other the Finnish results may not necessarily be applicable elsewhere. Even so, the similarity of living conditions and the high prevalence of overweight in Finland ${ }^{3}$ and in other industrialised countries ${ }^{15}$ suggest that overweight may have similar health implications in other populations.

We conclude that overweight is not an innocuous condition but a major preventable and treatable cause of ill health and disability in affluent populations.

\footnotetext{
1 Simopoulos AP, van Itallie TB. Body weight, health, and longevity. Ann Intern Med 1984;100:285-95.

2 Reunanen A, Aromaa A, Pyörälä K, et al. The Social Insurance Institution's coronary heart disease study. Acta Med Scand 1983;suppl 673:1-120.

3 Rissanen A, Heliövaara M, Aromaa A. Overweight and anthropometric changes in adulthood: a prospective study of 17000 Finns. Int $f$ Obes 1988;12:329-39.

4 Rissanen A, Heliövaara M, Knekt P, et al. Weight and mortality in Finnish men. Fournal of Clinical Epidemiology 1989;42:781-9.

5 Rissanen A, Knekt P, Heliövaara M, et al. Weight and mortality in Finnish women. fournal of Clinical Epidemiology (in press).

6 Kalbfleisch JD, Prentice RL. The statistical analysis of failure time data. New Yalbfleisch JD, Prentice

York: Wiley, 1980.
Miettinen OS. Proportion of disease caused or prevented by a given exposure, trait or intervention. Am f Epidemiol 1974;99:325-32.

8 Wadden TA, Stunkard AJ. Social and psychological consequences of obesity. Ann Intern Med 1985;103:1062-7.

9 Stewart AL, Brook RH. Effects of being overweight. Am J Public Healt 1983;7:171-8.

10 Bennett W. Dietary treatments of obesity. Ann NY Acad Sci 1987;499:250-63.

11 Anonymous. Men, women, and obesity [Editorial]. Br Med $\mathcal{F}$ 1974;iv:249-50.

12 Mason JE, Stampfer J, Hennekens CH, Willett WC. Body weight and longevity. FAMA 1987;257:353-8.

13 Harrison G. Height-weight tables. Ann Intern Med 1984;100:989-94.

14 Vinni K, Hakama M. Healthy worker effect in the total Finnish population. Brf Ind Med 1982;8:153-8.

15 Millar WJ, Stephens TS. The prevalence of overweight and obesity in Britain, Canada, and United States. Am F Public Health 1987;77:38-41.

(Accepted 29 fune 1990)
}

\title{
Trial of brief intermittent neuroleptic prophylaxis for selected schizophrenic outpatients: clinical and social outcome at two years
}

\author{
A G Jolley, S R Hirsch, E Morrison, A McRink, L Wilson
}

Department of Psychiatry, Charing Cross Hospital, London W6 8RF A G Jolley, MRCPSYCH, consultant psychiatrist

Department of Psychiatry, Charing Cross and Westminster Medical School, London W6 8RF S R Hirsch, FRCPSYCH, professor of psychiatry

E Morrison, RMN, community psychiatric nurse

A McRink, RMN, community psychiatric nurse

$\mathrm{L}$ Wilson, $\mathrm{MRCPSYCH}$, research worker

Correspondence to:

Professor Hirsch.

BrMed f 1990;301:837-42

\section{Abstract}

Objective-To evaluate a novel approach to the prophylaxis of schizophrenic relapse characterised by administration of brief courses of neuroleptic for the earliest non-psychotic signs of relapse (prodromal symptoms).

Design - Two year follow up of subjects randomised, double blind, to receive either active (control group) or placebo (intermittent group) depot neuroleptic medication. Both groups received brief courses of oral neuroleptic when prodromal symptoms or relapse occurred.

Setting-Psychiatric outpatient department, Charing Cross Hospital, London.

Subjects -54 Stable patients in remission who met the American Psychiatric Association's DSM-III criteria for schizophrenia on the basis of case notes.

Main outcome measures-Survival without relapse, survival without hospitalisation, point prevalence of extrapyramidal side effects and tardive dyskinesia, structured assessment of social functioning (social adjustment scale II), and frequency of prodromal symptoms.

Results - Of 19 relapses recorded over two years, $10(53 \%)$ were preceded by non-psychotic prodromal signs. Survival rates for both relapse and hospitalisation were worse with intermittent treatment than continuous treatment over the two year follow up: $92 \%$ of controls and only $54 \%$ of patients given intermittent treatment survived the two year period without hospitalisation. Prolonged or frequent relapses as well as episodes of prodromal symptoms were more frequent with intermittent treatment. Lower scores for extrapyramidal side effects were recorded in the intermittent treatment group, but periodic assessments of social functioning failed to show any social advantages from this.

Conclusion-The findings are at variance with a previous report of one year follow up in this cohort and attest to the superiority of continuous depot neuroleptic prophylaxis in preventing both psychotic and neurotic or dysphoric morbidity in schizophrenia.

\section{Introduction}

Over the past decade concern has mounted over the adverse effects of neuroleptic drugs used in the prophylaxis of schizophrenic relapse. This strategy is well known to reduce the risk of exacerbating symptoms, ${ }^{1}$ but many authors have highlighted the wider context in which outcome of treatment for the condition should be evaluated and have pointed to potentially deleterious consequences of drug exposure for patients' general wellbeing and social adjustment. Of principal concern have been the occurrence of tardive dyskinesia and distressing extrapyramidal side effects - these side effects have been linked to 
depressive and dysphoric symptoms, ${ }^{23}$ impairment of social function, ${ }^{4}$ and exacerbation of the negative symptoms of the illness.

This wider perspective on the outcome of treatment has led to a search for methods of prophylaxis that minimise drug exposure and toxic effects. Among the strategies proposed is the use of brief intermittent courses of neuroleptic drugs that are started at the earliest sign of deterioration of symptoms. Several groups have confirmed the feasibility of this strategy, ${ }^{6-11}$ and Carpenter and colleagues showed in an open comparative trial that outcome with intermittent treatment for early signs of relapse is similar in many respects to outcome with continuous treatment over a two year period. ${ }^{12}$ In their study intermittent treatment was associated initially with more frequent hospitalisation, but both the frequency and duration of hospitalisation and the final outcome over two years (as measured by positive symptoms, social and work performance, and the course of negative symptoms) were much the same in the intermittent and continuous treatment groups.

We previously reported the results of a double blind controlled study of intermittent treatment for early signs of schizophrenic relapse. ${ }^{11}$ The principal hypothesis of this study was that intermittent treatment would lead to reduction in persistent side effects such as tardive dyskinesia and in extrapyramidal side effects. We hypothesised that withdrawal from continuous medication would, overall, improve social functioning but that such improvement would probably be at the expense of more frequent episodes of deterioration of symptoms. It was reasoned that with early recognition and treatment such episodes could be attenuated so that serious relapse, as indicated by hospitalisation, would be no more frequent than with continuous treatment.

This report focuses on the two year outcome for the same group of patients and incorporates an evaluation of the effects of the treatment strategies on overall social functioning.

\section{Methods}

A previous report contains a more detailed description of the subjects and methods of this study. ${ }^{11}$

\section{SUBJECTS}

The subjects were 54 stable schizophrenic patients in remission who met DSM-III criteria for schizophrenia ${ }^{13}$ on the basis of case notes. All had been free of florid symptoms (delusions, hallucinations, bizarre behaviour, and thought disorder) for at least six months and had been stabilised for at least two months on a fixed dose of depot fluphenazine decanoate. All were referred by clinicians who thought that the patients might benefit from the brief intermittent treatment approach.

\section{DESIGN}

The patients were randomised into intermittent treatment $(n=27)$ and control $(n=27)$ groups. Controls continued to receive pretrial doses of depot neuroleptic, and in the intermittent treatment group equivalent doses of placebo injections were substituted under double blind conditions.

Both groups received group teaching sessions about schizophrenia and in particular about early signs of relapse. The nearest relative or cohabitee (when possible) was also invited to these sessions.

For the purposes of the study, relapse was defined as the re-emergence of florid psychotic symptoms (delusions, hallucinations, bizarre behaviour, or thought disorder) or a deterioration of symptoms sufficient to warrant hospitalisation. Prodromal symptoms were defined on a clinical basis as the emergence of neurotic or dysphoric symptoms persisting for two days or more and causing noticeable distress to the patient.

During the course of the study the patients were seen every four weeks alternately by a psychiatrist and a community psychiatric nurse. Additional visits were made to monitor patients who had relapsed, developed prodromal symptoms, failed to keep an appointment, or missed an injection. All had a 24 hour source of telephone contact with a member of the research team.

Additional oral haloperidol was given to patients in both groups who developed prodromal symptoms or relapse. Dose was flexible but usually in the range of $5-10 \mathrm{mg} /$ day. Dose of depot neuroleptic was converted to haloperidol equivalents on the basis of a notional equipotency of $1 \mathrm{mg}$ of fluphenazine decanoate intramuscularly and $2.62 \mathrm{mg}$ of haloperidol orally. ${ }^{14}$

Treatment of prodromal symptoms continued for up to two weeks unless relapse had occurred. Treatment of relapse was continued until four weeks after the remission of symptoms.

Patients were withdrawn from double blind treatment and early intervention if they refused to comply with the treatment programme or if relapse was prolonged (more than eight weeks) or frequent (more than two relapses in six months).

\section{MEASURES}

A modified Simpson-Angus scale ${ }^{15}$ was rated six monthly to determine the prevalence of specific extrapyramidal side effects and global measures of parkinsonism and "non-liveliness." The prevalence of tardive dyskinesia was evaluated with the AIMS scale, ${ }^{16}$ also at six monthly intervals. Tardive dyskinesia was rated as present if global severity of abnormal movement was rated as 2 or higher and was accompanied by a score of 2 or higher on any individual orofacial movement.

Assessments of social function were made at baseline and thereafter at three monthly intervals with the social adjustment scale II (SAS-II). ${ }^{1} 17$ This scale takes specific account of issues in the lives of schizophrenic patients such as unemployment, lack of spouse and children, special living arrangements, and poor daily living skills. The scale consists of 52 items which measure either instrumental or expressive role performance in eight areas of adjustment: work (as housewife, student, or wage earner), relationship with principal household member, parental role, relationship with external family, social and leisure activities, conjugal and non-conjugal sexual activity, romantic involvement, and personal wellbeing. The last area, personal wellbeing, includes items such as appearance, grooming, and ability to care for oneself. Each item was rated on a five point scale, with a higher score indicating a greater level of impairment. Area means were calculated from the scores on individual groups of items. Global judgments in five areas of functioning were also made on the basis of the rater's evaluation of the patient in comparison with her concept of a normal person in the community. An overall social function score was calculated by summing area and global scores for each individual patient and dividing by the number of areas in which ratings could be made in the patient.

Ratings on the social adjustment scale were made during interviews with the patients conducted by the community psychiatric nurse during visits to the patients' homes. Previous work shows good agreement between reports by patients and their nearest relative or cohabitee of social adjustment on the scale. ${ }^{18}$

\section{STATISTICAL METHODS}

Non-parametric tests of significance were used in all comparisons: $\chi^{2}$ with Yates's correction and the Mann-Whitney $U$ test for independent samples and 
Wilcoxon's signed rank test for non-independent samples.

The effects of the intermittent and continuous dosing strategies on relapse and hospitalisation rates were evaluated using life table methods. The cumulative distributions of relapses and hospitalisations in each group were calculated using the product limit method, ${ }^{19}$ in which the cumulative proportion remain ing without relapse (or hospitalisation) is estimated each time a patient suffers a relapse or is hospitalised. The method takes account of patients who have been dropped out of the study and who thus no longer remain at risk. This analysis was performed using biomedical programs data package life table software..$^{20}$

\section{Results}

\section{FOLLOW UP OF PATIENTS}

Table I shows the number of patients withdrawn from double blind treatment in the two study groups and outlines the reasons for withdrawal. Notably some eight subjects on intermittent treatment $(30 \%)$ and only one control subject (4\%) were withdrawn because

TABLE I-Reasons for withdrawing patients from double blind treatment. Figures are numbers (percentages)

\begin{tabular}{lcc}
\hline & $\begin{array}{c}\text { Control } \\
\text { group } \\
(\mathbf{n}=27)\end{array}$ & $\begin{array}{c}\text { Intermittent } \\
\text { treatment } \\
\text { group } \\
(\mathbf{n}=27)\end{array}$ \\
\hline $\begin{array}{l}\text { Relapse } \\
\quad \text { Prolonged }(>8 \text { weeks })\end{array}$ & $1(4)$ & $8(30)$ \\
$\begin{array}{l}\text { Frequent }(>1 \text { in } 6 \text { months }) \\
\text { Refused to comply }\end{array}$ & $1(4)$ & $5(19)$ \\
Died & $6(22)$ & $3(11)$ \\
Disappeared & $2(7)$ & $2(19)$ \\
\hline Total patients withdrawn & $9(33)$ & $15(56)$ \\
\hline$\chi^{2}=5 \cdot 21, \mathrm{df}=1, \mathrm{p}=0 \cdot 023$. & &
\end{tabular}

TABLE II-Outcome of all patients followed up for two years

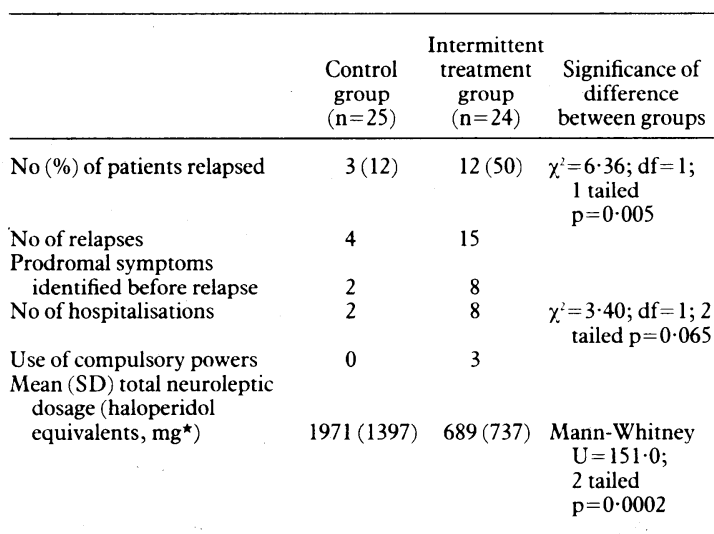

$\star$ Based on dose equivalence of $1 \mathrm{mg}$ intramuscular fluphenazine decanoat and $2.62 \mathrm{mg}$ oral haloperidol.

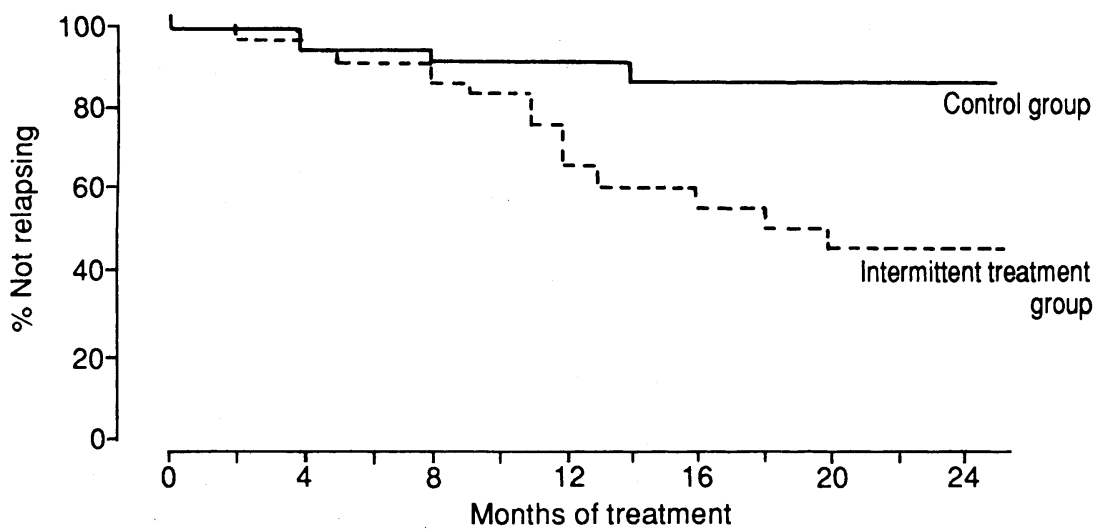

$\begin{array}{llllllllllll}\text { No at risk: } 54 & 51 & 48 & 46 & 44 & 42 & 34 & 31 & 30 & 29 & 27 & 25\end{array}$

FIG 1-Survival analysis of relapse in intermittent treatment and control groups of prolonged or frequent relapse, indicating a significant advantage for the control treatment $\left(\chi^{2}=5 \cdot 21\right.$, $\mathrm{df}=1, \mathrm{p}=0.023$ ).

Of the 54 patients entering the study, 49 were followed up for two years from its start. Of the five patients not followed up for two years, three were receiving intermittent treatment and two were controls.

Two patients in the control group died in the course of the study. In one case the circumstances of death suggested suicide but the patient had not made emergency contact with the research team and there had been no evidence of relapse or prodromal symptoms before the death. In the other case death was attributable to an acute physical illness, and the patient had been withdrawn from the study at the time of diagnosis.

Two patients receiving intermittent treatment disappeared in the course of the study and could not be traced. Before disappearing both had been clinically stable and one had expressed a desire to visit relatives abroad. One additional patient receiving intermittent treatment refused all attempts at follow up.

Of the 49 patients for whom two year follow up data were available, 19 had been withdrawn from double blind treatment before the end of the two year study period. Thirteen of these were re-established on depot neuroleptic drugs, and two patients in the intermittent treatment group and four controls received no further neuroleptics.

Table II shows the clinical outcome for patients who were followed up for two years from entry into the study. Relapse and hospitalisation were significantly more common in the intermittent group than in controls, and hospitalisation was fourfold greater over the two year period. Three patients in the intermittent group and one in the control group relapsed twice within six months. Despite more frequent relapses, however, total exposure to neuroleptics was significantly lower with intermittent treatment than continuous treatment.

SURVIVAL ANALYSIS FOR RELAPSE AND HOSPITALISATION

Figure 1 is a survival curve that shows the proportion of patients in each group who remained free of relapse during up to two years of double blind treatment. Over the two year period patients receiving intermittent treatment had a significantly lower survival rate than the controls $(48 \% v 87 \%$; Mantel$\operatorname{Cox}=7 \cdot 14, \mathrm{df}=1, \mathrm{p}=0 \cdot 008$ ).

A similar analysis is shown in figure 2 for the proportion of patients surviving without hospitalisation during double blind treatment. Survival rates were again significantly lower in the group receiving intermittent treatment than in controls $(59 \% v 92 \%)$; Mantel-Cox $=4 \cdot 60, \mathrm{df}=1, \mathrm{p}=0.032$ )

\section{PRODROMAL EPISODES}

Table III shows the outcome for patients who completed two years of double blind treatment and early intervention for prodromal symptoms of relapse. This is perhaps the most salient measure of the effect of the treatment strategy for those able to continue on it. Significantly more patients receiving intermittent treatment than controls experienced prodromal symptoms over the two year period. This is reflected also in the significantly greater number of unscheduled contacts with the research team in this group. Total drug exposure in the intermittent treatment group was significantly lower than in controls receiving continuous treatment despite more frequent administration of oral haloperidol for prodromal symptoms and relapse in patients receiving intermittent treatment.

Of 19 relapses recorded during the two year course of the study (table II), prodromal symptoms were 


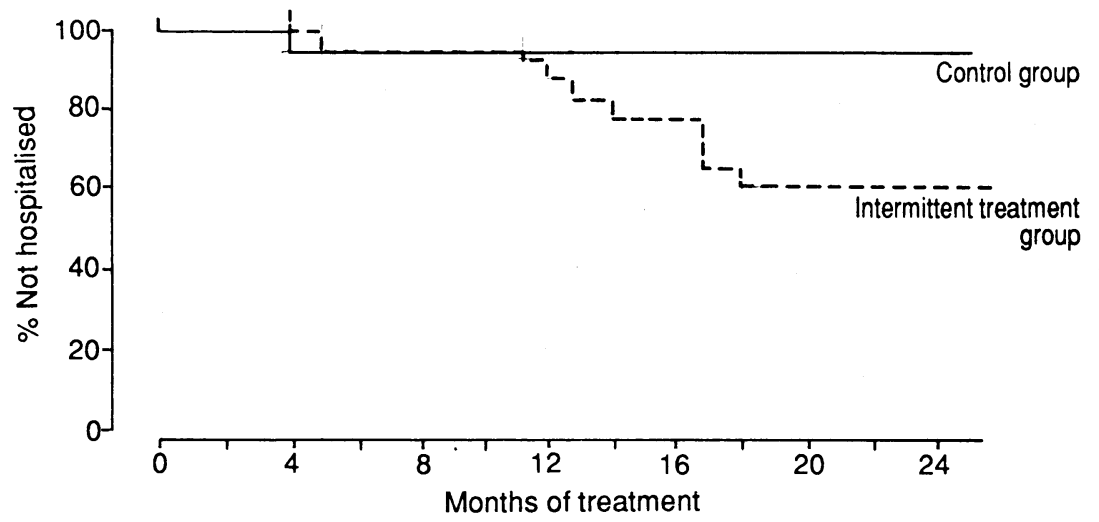

No at risk: $\begin{array}{llllllllllll}54 & 52 & 48 & 45 & 44 & 46 & 37 & 32 & 32 & 29 & 27 & 26\end{array}$

FIG 2-Survival analysis of hospitalisation in intermittent treatment and control groups

TABLE III-Outcome for patients completing two years of double blind treatment

\begin{tabular}{|c|c|c|c|}
\hline & $\begin{array}{l}\text { Control group } \\
(\mathrm{n}=18)\end{array}$ & $\begin{array}{l}\text { Intermittent } \\
\text { treatment group } \\
(\mathrm{n}=12)\end{array}$ & $\begin{array}{c}\text { Significance of } \\
\text { difference between } \\
\text { groups }\end{array}$ \\
\hline No $(\%)$ of patients with prodromal symptoms & $5(28)$ & $10(83)$ & $\begin{array}{c}\chi^{2}=6.81 ; d f=1 \\
p=0.009\end{array}$ \\
\hline $\begin{array}{l}\text { Mean (SD) total neuroleptic dosage (haloperidol } \\
\text { equivalents, } \mathrm{mg}^{\star} \text { ) }\end{array}$ & $1616(598)$ & $298(249)$ & $\begin{array}{l}\text { Mann-Whitney } \\
U=3.0 ; p<0.0001\end{array}$ \\
\hline Total No of unscheduled interventions & 26 & 91 & $\begin{array}{l}\text { Mann-Whitney } \\
\quad U=37.0 ; p=0.001\end{array}$ \\
\hline
\end{tabular}

$\star$ Based on dose equivalence of $1 \mathrm{mg}$ intramuscular fluphenazine decanoate and $2.62 \mathrm{mg}$ oral haloperidol

TABLE IV-Mean scores for extrapyramidal side effects. Values in parentheses are ranges

\begin{tabular}{|c|c|c|c|}
\hline & $\begin{array}{c}\text { Control group } \\
(n=18)\end{array}$ & $\begin{array}{c}\text { Intermittent } \\
\text { treatment group } \\
(\mathrm{n}=12)\end{array}$ & Mann-Whitney U test \\
\hline Baseline & $4 \cdot 5(0 \cdot 0-10 \cdot 0)$ & $2 \cdot 7(0 \cdot 0-7 \cdot 0)$ & $\mathrm{U}=70 \cdot 5 ; \mathrm{p}=0.109$ \\
\hline 6 Months & $3 \cdot 1(0 \cdot 0-9 \cdot 0)$ & $1.0(0 \cdot 0-6 \cdot 0)$ & $\mathrm{U}=56.0 ; \mathrm{p}=0.023$ \\
\hline 1 Year & $3 \cdot 6(0 \cdot 0-8 \cdot 0)$ & $0.5(0 \cdot 0-5 \cdot 0)$ & $\mathrm{U}=46.5 ; \mathrm{p}=0.008$ \\
\hline 18 Months & $3 \cdot 6(0 \cdot 0-8 \cdot 0)$ & $0.8(0 \cdot 0-8 \cdot 0)$ & $\mathrm{U}=49 \cdot 0 ; p=0.007$ \\
\hline 2 Years & $2 \cdot 5(0 \cdot 0-9 \cdot 0)$ & $0 \cdot 6(0 \cdot 0-6 \cdot 0)$ & $\mathrm{U}=59.0 ; \mathrm{p}=0.025$ \\
\hline
\end{tabular}

TABLE V-Point prevalence of tardive dyskinesia

\begin{tabular}{lrrrrc}
\hline & \multicolumn{2}{c}{ Control group } & & \multicolumn{2}{c}{$\begin{array}{c}\text { Intermittent } \\
\text { treatment group }\end{array}$} \\
\cline { 2 - 3 } \cline { 5 - 6 } & No $(\%)$ & $\begin{array}{c}\text { No being } \\
\text { treated }\end{array}$ & & No (\%) & $\begin{array}{c}\text { No being } \\
\text { treated }\end{array}$ \\
\hline Baseline & $9(33)$ & 27 & & $8(30)$ & 27 \\
6 Months & $10(40)$ & 25 & & $7(30)$ & 23 \\
1 Year & $12(55)$ & 22 & & $5(24)$ & $21^{\star}$ \\
18 Months & $8(44)$ & 18 & & $5(36)$ & 14 \\
2 Years & $8(44)$ & 18 & & $3(25)$ & 12 \\
End point $\dagger$ & $12(44)$ & 27 & & $8(30)$ & 27
\end{tabular}

$\star \chi^{2}=3 \cdot 057, \mathrm{df}=1, \mathrm{p}=0.080$

TTime at which patient was withdrawn from double blind treatment. Mean duration of double blind treatment was $19 \cdot 3$ months in controls and $17 \cdot 1$ months in the intermittent treatment group.

TABLE VI-Comparison of social function $(S A S-I I)$ at baseline

\begin{tabular}{|c|c|c|c|c|}
\hline & \multicolumn{2}{|c|}{ Control group } & \multicolumn{2}{|c|}{ Intermittent treatment group } \\
\hline & Mean (range) & $\mathrm{No}^{\star}$ & Mean (range) & $\mathrm{No}^{\star}$ \\
\hline \multicolumn{5}{|l|}{ Area scores: } \\
\hline Work & $2 \cdot 13(0 \cdot 14-4 \cdot 33)$ & 27 & $1 \cdot 44(0 \cdot 29-4 \cdot 33)$ & 27 \\
\hline Principal household member & $0.59(0.00-1.60)$ & 18 & $0.55(0.00-1.40)$ & 17 \\
\hline Sexual adjustment & $2 \cdot 12(0 \cdot 00-4 \cdot 00)$ & 21 & $1.94(0.00-4 \cdot 00)$ & 20 \\
\hline Parental & $1.62(0 \cdot 86-2 \cdot 80)$ & 19 & $1 \cdot 61(0 \cdot 00-2 \cdot 67)$ & 24 \\
\hline External family & $0 \cdot 21(0 \cdot 00-1 \cdot 60)$ & 19 & $0.33(0 \cdot 00-1.60)$ & 21 \\
\hline Social leisure & $1.52(0.67-2.57)$ & 27 & $1.54(0 \cdot 67-2 \cdot 50)$ & 27 \\
\hline Romantic involvement & $1 \cdot 53(0 \cdot 00-4 \cdot 33)$ & 13 & $2 \cdot 72(0 \cdot 00-4 \cdot 50)$ & 15 \\
\hline Personal wellbeing & $1 \cdot 08(0 \cdot 50-2 \cdot 25)$ & 27 & $0.83(0.00-1.75)$ & $27 \dagger$ \\
\hline \multicolumn{5}{|l|}{ Global scores: } \\
\hline Work & $2 \cdot 58(0-4)$ & 27 & $2 \cdot 33(2-3)$ & 27 \\
\hline Household & $2 \cdot 29(2-4)$ & 18 & $2 \cdot 56(2-4)$ & 20 \\
\hline External family & $2 \cdot 74(2-6)$ & 19 & $3.04(2-6)$ & 21 \\
\hline Social leisure & $3 \cdot 21(3-5)$ & 27 & $3 \cdot 29(2-4)$ & 27 \\
\hline General adjustment & $2 \cdot 95(2-4)$ & 27 & $2 \cdot 96(2-4)$ & 27 \\
\hline Social function score & $2 \cdot 14(1 \cdot 35-3 \cdot 59)$ & 27 & $1.97(0 \cdot 97-3 \cdot 25)$ & 27 \\
\hline
\end{tabular}

identified before relapse in $10(53 \%)$. During the first year 11 relapses were recorded, of which eight $(73 \%)$ were preceded by prodromal symptoms. In the second year eight relapses were recorded, but prodromal symptoms were identified before only two of these $(25 \%)$. We are not able to say if prodromal symptoms were less frequent in the second year, or if patients were only less vigilant about reporting them.

In all, 62 prodromal episodes were recorded. Of these, $10(16 \%)$ occurred before relapse whereas the remaining $52(84 \%)$ bore no clear relation to relapse. Details of the nature and course of these prodromal symptoms will be presented elsewhere.

\section{SIDE EFFECTS}

An overall rating of extrapyramidal side effects was obtained by summing all individual items on the extrapyramidal rating scale to produce a total symptom score for each patient (table IV). Scores were higher at baseline in controls than in the intermittent treatment group but this difference was not significant. Significantly higher scores were recorded in the controls than in the group receiving intermittent treatment at each point thereafter.

Point prevalence data for tardive dyskinesia are shown in table $\mathrm{V}$. At one year follow up there was a trend $(p=0.08)$ towards a lower prevalence of tardive dyskinesia in the intermittent treatment group. This was not found in patients completing two years of the study, and an analysis of the prevalence of tardive dyskinesia at the end of double blind treatment did not find significant differences between the two treatment groups.

\section{SOCIAL FUNCTION}

Table VI gives a comparison of social function ratings at baseline. The intermittent treatment and control groups were well matched in overall social function score, in global ratings, and in all areas of functioning except personal wellbeing. Significantly lower scores were found for wellbeing in the intermittent treatment group, indicating a better level of personal wellbeing at baseline in subjects receiving intermittent treatment than in controls.

Comparison of overall social function scores at three monthly follow up assessments did not show any significant differences between experimental and control groups at any point in the study (MannWhitney U tests).

Detailed analysis of the eight adjustment area scores and global ratings will be presented elsewhere. Despite a number of significant differences within and between the groups in these items no consistent pattern of change over time emerged in either group.

\section{PATIENTS WITHDRAWN FROM DOUBLE BLIND TREATMENT}

The 24 patients who failed to complete two years of double blind treatment and early intervention were compared with the remainder of the study sample in respect of the baseline clinical and sociodemographic characteristics noted in our previous report. ${ }^{11}$ There were no significant differences between drop outs and those who completed two years of double blind treatment in any of these characteristics.

\section{Discussion}

In our previous report we found that over a one year period the frequency of hospitalisation with intermittent treatment was comparable with that found with continuous treatment with neuroleptic drugs. ${ }^{11}$ The present report, which examined the two year follow up, found a significant disadvantage for the intermittent treatment group, who had significantly 
more hospitalisation than controls receiving depot fluphenazine decanoate.

Our findings are at variance with those of Carpenter et $a l,{ }^{12}$ who found comparable survival without hospitalisation in intermittent and continuous treatment groups over a two year period. This may in part be explained by the more extensive psychosocial intervention undertaken in the study of Carpenter and colleagues. Patients assigned to intermittent treatment in their study were provided with $\mathbf{4 5}$ minutes' access to a "primary therapist" weekly during the study, and this therapist saw the patient and family (or partner) for six sessions early in the course of treatment. By contrast, patients assigned to continuous treatment had no family intervention and saw a "pharmacotherapist" for a brief interview only in alternate weeks. In our own study, both experimental and control groups received identical psychoeducational sessions at the beginning of the study. Only a single session was provided, and routine follow up took place monthly in both groups, with additional interventions contingent on symptoms in either group. The poorer result for the intermittent treatment group in the second year of our study may reflect the need for more extensive and ongoing psychosocial work with both patients and families used by Carpenter $e t$ al if the approach is to be successful in the longer term. Although all our patients were asked about prodromal symptoms and reminded at each monthly assessment of the importance of contacting the research team when such symptoms developed, there was no systematic attempt to reacquaint patients and relatives with the paradigm of the study after the initial teaching session.

It is also noteworthy that in the study of Carpenter and colleagues hospitalisation in the intermittent treatment group was more common in the first year whereas our intermittent treatment patients required hospitalisation more often in the second year. In our study all patients were initially stabilised on depot neuroleptic drugs. It is well known that depot drugs persist in body fluids for many months after treatment is discontinued. ${ }^{21}$ This may have conferred some protective effect against severe relapse in the first year of our study. Carpenter and colleagues did not report the frequency that patients were given depot drugs before starting in their study and it may be that this frequency was lower in their study population. Also, patients in the study of Carpenter and colleagues were withdrawn from neuroleptics for one month before beginning the study. Both of these factors may have led to lower initial levels of neuroleptics in the intermittent treatment group and hence less protective effect in the first year.

The brief intermittent approach was associated in our study with a significantly lower rate of survival without relapse over both the first and second years when compared with continuous treatment with neuroleptics. Over the first year, prolonged or frequent relapses were not significantly more common with intermittent treatment, but this result did not obtain over the two years of the study. Prolonged relapse was more frequent with intermittent treatment: only one patient $(4 \%)$ on continuous treatment and five (19\%) on intermittent treatment were withdrawn from the trial for this reason. Frequent relapse was also more common with intermittent treatment: three patients treated with this strategy had two relapses within six months, but no control patients had relapses.

During the first year of the study, $73 \%$ of relapses were preceded by identified prodromal symptoms; during the second year this figure fell to $25 \%$. An assumption inherent in the intermittent treatment approach is that early detection and treatment of decompensation may attenuate relapse. If this assumption is correct the relative failure to identify and treat early signs of decompensation in the second year may account for the greater frequency of severe relapse later in the study. With routine follow up at monthly intervals considerable reliance was placed on patients and their families or cohabitees to identify and seek assistance for emergent prodromal symtoms. The lack of success in this respect in the second year suggests that a single teaching session at the beginning of the study does not provide patients and families with an adequate grasp of the paradigm of the intermittent treatment strategy. Ongoing psychoeducational intervention should be an essential component of further studies in this area.

In addition to a greater psychotic morbidity, intermittent treatment led to more non-specific neurotic and dysphoric episodes (prodromal episodes) in both years of follow up. These were all treated with oral haloperidol. Over the two years of the study only $16 \%$ of such episodes were followed by relapse. Though the greater frequency of such episodes when patients are not receiving drug treatment suggests that they may form part of the schizophrenic process, the evaluation of this hypothesis must await a study in which patients are randomly treated with placebo or a neuroleptic agent for a brief period to see if the neuroleptic drug that we used routinely in this study really accounted for the self limiting nature of most of the dysphoric or neurotic episodes that we observed in this study.

The reduction in extrapyramidal side effects noted in the first year was also found among those patients who completed two years of double blind treatment. The trend toward reduction of tardive dyskinesia found during the first year could not be confirmed either in an end point analysis of all cases entered into the study or in the subgroup of patients who completed two years of double blind treatment, possibly because so many had further episodes of treatment with neuroleptic drugs during the study.

Despite a reduction in extrapyramidal side effects there was no overall improvement in social function in patients successfully maintained on intermittent treatment over the two year period. The failure to show these advantages in the intermittent treatment group as a whole does not obviate the fact that in certain patients within the group some improvements in wellbeing and social function were noted during the course of the study. It should be recalled, however, that the study sample consisted of stable patients in remission who clinicians felt might benefit from the intermittent treatment strategy. It is unclear from this study what, if any, further criteria might be employed in selecting appropriate patients for this treatment approach.

The principal findings of this investigation are greater psychotic and non-psychotic morbidity, more frequent hospitalisation, and the absence of any overall social gains with intermittent treatment. These findings attest to the superiority of continuous neuroleptic prophylaxis for most patients suffering from schizophrenia. Further studies incorporating more extensive psychoeducation and monitoring may yet show a place for intermittent treatment in selected patients. The reduction in extrapyramidal side effects with intermittent treatment suggests that the strategy might be useful for those patients particularly troubled by such side effects. The additional commitment of staffing resources that would be required to implement the strategy widely in clinical practice, however, may well prove unrealistic within current levels of health service provision.

This study was funded by grants from the Department of Health and Social Services, North West Thames Regional Research Fund, and the Priory Hospital, Roehampton. Depot fluphenazine decanoate and placebo were supplied by E R Squibb and Sons. We thank Drs H McKee, S Baxter, C Hallstrom, G Oppenheim, C McEvedy, R Kent, and R 
Reid for help in recruiting patients into the study and Dr K Macrae for statistical advice.

1 Hirsch SR. Clinical treatment of schizophrenia. In: Bradley P, Hirsch SR, eds. Psychopharmacology and treatment of schizophrenia. Oxford: Oxford University Press, 1986.

2 Van Putten T, May PRA. "Akinetic depression" in schizophrenia. Arch Gen Psychiatry 1978;35:1101-7.

3 Van Putten T, Marder SR. The dysphoria syndrome and its relation to EPS In: Pichot $\mathrm{P}$, Berner $\mathrm{P}$, Wolf $\mathrm{R}$, Thau K, eds. Psychiatry: the state of the art. In: Pichot P, Berner P, Wolf R, Thau K,

4 Falloon I, Watt DC, Shepherd M. The social outcome of patients in a trial of long term continuation therapy in schizophrenia: pimozide versus fluphenarine. Psychol Med 1978:8:265-74.

5 Kane JM, Rifkin A, Woerner $M$, Sarantakos $S$. Dose response relationships in maintenance drug treatment for schizophrenia. Psychopharmacol Bull 1986;6:205-35

6 Herz MI, Szymanski HV, Simon J. Intermittent treatment for stable schizophrenic outpatients: an alternative to maintenance medication. Am f Psychiatry 1982;139:918-22.

7 Herz MI, Glazer W, Mirza M, Mostert M, Hafez H. Treating prodromal episodes to prevent relapse in schizophrenia. Br f Psychiatry 1989;155 (suppl 5):123-7

8 Carpenter WI, Stephens WT, Rey A, Hanlon TE, Heinrichs DW. Early intervention versus continuous pharmacotherapy in schizophrenia. Psychopharmacol Bull 1982;18:21-3.

9 Pietzcker A, Gaebel W, Kopcke M, et al. A German multicentre study of the neuroleptic long term therapy of schizophrenic patients. Pharmacopsychiatry 1986;19:161-6.

10 Hirsch SR, Jolley AG, Manchanda R, McRink A. Early intervention medication as an alternative to continuous depot treatment in schizophrenia; preliminary report. In: Strauss J, Boker W, Brenner H, eds. Psychosocia treatment of schizophrenia. Berne: Hans Huber, 1987.
11 Jolley AG, Hirsch SR, McRink A, Manchanda R. Trial of brief intermittent neuroleptic prophylaxis for selected schizophrenic outpatients; clinical outcome at one year. Br Med f 1989;298:985-90.

12 Carpenter WI Heinrichs DW Hanlon TE. A comparative trial of pharmacologic strategies in schizophrenia. Am $\mathcal{F}$ Psychiatry 1987;144:1466-70.

13 American Psychiatric Association. Diagnostic and statistical manual of mental disorders. 3rd ed. Washington, DC: American Psychiatric Association, 1980 14 Davis J. Comparative doses and costs of antipsychotic medication. Arch Gen Psychiatry 1976;33:858-61.

15 Knights A, Okasha MS, Salih M, et al. Depressive and extrapyramidal symptoms and clinical effects: a trial of fluphenazine versus flupenthixol in the maintenance of schizophrenic outpatients. Br J Psychiatry 1979;135 515-23.

16 Guy W. ECDEU assessment manual for psychopharmacology. Rockville, Maryland: National Institute of Mental Health, Psychopharmacology Research Branch, 1976.

17 Schooler N, Hogarty G, Weissman M. Social adjustment scale II (SAS-II). In Resource materials for community mental health programme evaluators. Rockville, Maryland: US Department of Health, Education and Welfare, 1979. ville, Maryland: US Department or

18 Glazer WM, Aaronson HS, Prusoff BA, Williams DH. Assessment of social adjustment in chronic ambulatory schizophrenics. F Nerv Ment Dis 1980 $168: 493-7$

19 Kaplan E, Meir P. Nonparametric estimation for incomplete observations. Journal of the American Statistical Association 1958;53:457-81.

20 Benedetti J, Yuen K, Young L. Life tables and survival function. In: Dixon W, ed. BMDP statistical software. Berkeley: University of California Press, 1981:19.1.

21 Wistedt B, Jorgensen A, Wiles D. A depot neuroleptic withdrawal study: plasma concentration of fluphenazine and flupenthixol and relapse frequency. Psychopharmacol Bull 1982;78:301-4.

(Accepted 29 fune 1990)

\section{Cost of surfactant replacement treatment for severe neonatal respiratory distress syndrome: a randomised controlled trial}

\section{T R J Tubman, H L Halliday, C Normand}

\begin{abstract}
Objective-To estimate the cost of treating babies with severe respiratory distress syndrome with natural porcine surfactant.

Design-Retrospective controlled survey.

Setting-Regional neonatal intensive care unit, Belfast.

Patients - 33 Preterm babies with severe respiratory distress syndrome who were enrolled in a European multicentre trial during 1985-7. 19 Babies were treated with surfactant and 14 served as controls.
\end{abstract}

Interventions-Treatment with natural porcine surfactant.

Main outcome measure-Cost associated with surfactant replacement treatment per extra survivor in the treatment group and cost per quality adjusted life year for each extra survivor.

Results-Fifteen (79\%) of the 19 treated babies and five $(36 \%)$ of the 14 control babies survived. On average, the control babies required 20 days in hospital compared with 61 days for the treated babies (or 91 days per extra survivor in the treatment group). The cost per extra survivor in the treatment group was $£ 13720$, with the cost per quality adjusted life year estimated at $£ 710$.

Conclusion-These costs compare favourably with those of established forms of treatment in adults. Thus surfactant replacement treatment for severe respiratory distress syndrome is fairly inexpensive and cost effective.

H L Halliday, FRCP consultant paediatrician

Health Care Research Unit, Queen's University of Belfast, Belfast

C Normand, DPHIL, director

Correspondence to:

Dr Tubman.
Several randomised controlled trials have shown that replacement treatment with natural surfactant is effective in the neonatal respiratory distress syndrome. ${ }^{1.3}$ Most studies have shown an improvement in survival rate without an increase in bronchopulmonary dysplasia $^{1-3}$ and with a reduction in the incidence of complications, particularly pulmonary interstitial emphysema, pneumothorax, and intraventricular haemorrhage. ${ }^{2-4}$ In some neonatal units surfactant replacement treatment has now become routine for babies with severe respiratory distress syndrome.

Recently information on the cost of providing neonatal intensive care has become available, ${ }^{5}$ although only a few reports refer to centres in the British Isles. ${ }^{6.9}$ Neonatal intensive care is expensive but seems to be cost effective, at least so far as infants weighing more than $1000 \mathrm{~g}$ are concerned. ${ }^{5}$ Few studies have looked specifically at the costs of surfactant replacement treatment. Maniscalco et al showed a saving of $\$ 18500$ because of a reduction in the need for ancillary services such as radiology and laboratory tests. ${ }^{10} \mathrm{~A}$ saving of $\$ 10000$ for each survivor was reported in a Canadian study."

The reduction in mortality brought about by surfactant replacement treatment has added to the number of babies surviving because of advances in neonatal intensive care. As these babies are usually very premature and of extremely low birth weight they spend long periods in hospital before being discharged, thus increasing demands for nursing and medical care. When new methods of treatment are introduced it is important to determine how they will affect budgeting policies. As part of a multicentre trial $^{3}$ we studied the cost of giving natural porcine surfactant to babies who had severe respiratory distress syndrome.

\section{Patients and methods}

The study was performed in the neonatal unit of the Royal Maternity Hospital, Belfast. This has provision for seven cots for level I and level II intensive care and 11 cots for special and nursery care. Intensive care and special care were as defined by the British Paediatric Association and British Association for Perinatal Paediatrics. ${ }^{12}$ Nursery care was similar to that defined by Sandhu et al..$^{7}$ and was taken to include special 